\title{
Manutenção de Desigualdades na Avaliação do Gênero na Psicologia Brasileira
}

\author{
Angelo Brandelli Costa ${ }^{1}$ \\ Programa de Pós-Graduação em Psicologia da Pontificia Universidade Católica \\ do Rio Grande do Sul, Porto Alegre, RS, Brasil \\ Henrique Caetano Nardi \\ Silvia Helena Koller \\ Instituto de Psicologia da Universidade Federal do Rio Grande do Sul, Porto Alegre, RS, Brasil \\ Optentia Research Focus Area North-West University, Vanderbijlpark, South Africa
}

\section{Resumo}

A partir da análise crítica da escala de Masculinidade e Feminilidade (M) da versão brasileira da Escala de Personalidade de Comrey (CPS), o objetivo deste estudo é recuperar o tratamento histórico que a psicologia feminista deu às ideias de sexo e gênero e seus desdobramentos. Além disso, pretende apontar para uma concepção de gênero autodesignada, não essencialista, pluralista e não patológica. Por fim, visa a analisar como o CPS é mantido como medida psicológica válida no contexto brasileiro em paralelo, contraditoriamente, com a defesa da igualdade de gênero. O uso do CPS no Brasil parece se relacionar ao fato de que os estudos feministas na psicologia social e a avaliação psicológica se consolidaram com poucas interfaces e com bases epistemológicas distintas. Conclui-se apontando que as práticas psicológicas, com ênfase as medidas de avaliação de gênero, sejam revistas à luz do conhecimento contemporâneo dos estudos de gênero e da psicologia feminista.

Palavras-chave: Avaliação psicológica, gênero, sexo, Escala de Personalidade de Comrey.

\section{Inequalities Maintenance in the Brazilian Psychology Gender Assessment}

\begin{abstract}
From the critical analysis of the Masculinity and Femininity scale (M) of the Brazilian version of Comrey Personality Scale (CPS), the aim of this study is to recover the historical treatment that feminist psychology gave to the ideas of sex and gender and its implications. It also aims to point to a self-designated, non essentialist, pluralistic and non pathological conception of gender. Finally, aims to analyze how the CPS is maintained as valid psychological measure in the Brazilian context in parallel, paradoxically, with the defense of gender equality. The use of CPS in Brazil seems to be related to the fact that, in this context, women's studies in social psychology and psychological assessment were consolidated with few interfaces and with distinct epistemological foundations. We conclude by pointing out that the psychological practices, with emphasis on gender assessment, must be reviewed in the light of contemporary gender studies and feminist psychology.
\end{abstract}

Keywords: Psychological assessment, gender, sex, Comrey Personality Scale.

Endereço para correspondência: Rua Ramiro Barcelos, 2600, Porto Alegre, RS, Brasil 90035-003. Fone: 33085066. E-mail: brandelli.costa@ufrgs.br

Apoio financeiro: Coordenação de Aperfeiçoamento de Pessoal de Nível Superior (CAPES) e Conselho Nacional de Desenvolvimento Científico e Tecnológico (CNPq). 


\section{Mantenimiento de Desigualdades en la Evaluación de Género en la Psicología Brasileña}

\section{Resumen}

Desde la análisis crítica de la escala de Masculinidad y Feminidad (M) de la versión brasileña de la Escala de Personalidad de Comrey (CPS), el objetivo de este estudio es recuperar el tratamiento histórico que la psicología feminista dio a las ideas de sexo y género y su implicaciones. También tiene como objetivo apuntar a una concepción autodesignada, no esencialista, pluralista y no patológica de género. Finalmente, tiene como objetivo analizar cómo el CPS se mantiene como una medida psicológica válidas en el contexto brasileño en paralelo, paradójicamente, con la defensa de la igualdad de género. El uso de CPS en Brasil parece estar relacionado con el hecho de que, en este contexto, los estudios de género en la psicología social y la evaluación psicológica se consolidaron con pocos puntos en común y con fundamentos epistemológicos distintos. Concluimos señalando que las prácticas psicológicas, principalmente la evaluación de género, deben ser revisados a la luz de los estudios de género contemporáneos y la psicología feminista

Palabras clave: Evaluación psicológica, gênero, sexo, Escala de Personalidad de Comrey.

Em 1970 um grupo de psicólogas norte-americanas lideradas por Phyllis Chesler e Nancy Henley organizaram uma manifestação na reunião anual da Associação Norte-americana de Psicologia (American Psychological Association [APA]). Elas exigiam reparação financeira no valor de um milhão de dólares pelos danos que as teorias psicológicas androcêntricas e misóginas causaram às mulheres. Reproduzimos aqui uma parte da declaração:

A psicologia tem sido criminosa em sua maneira de se relacionar com as mulheres. Ela tem perpetuado as ideias de supremacia masculina presentes na psicologia freudiana, aceitando sem bases científicas pressupostos cruéis sobre determinação biológica dos papeis sexuais; ela participou da prisão psicológica e física de inúmeras mulheres quando as rotulou de mentalmente incapazes por causa de sua recusa em cumprir as exigências injustas e ilegítimas impostas a elas. Chegou o momento para os/as profissionais da psicologia e da saúde começarem a reparar os danos que causaram e de inverter a direção das forças já em curso que visam a aprisionar e assassinar as mentes e os corpos das mulheres. (Pickren \& Rutherford, 2010, p. 266)

É evidente que esse não foi um evento isolado. Ele ocorre no contexto da segunda onda do feminismo nos Estados Unidos muito influenciada, por exemplo, por Betty Friedan, ativista cofundadora da Organização Nacional das Mulheres, psicóloga e autora de "A Mística Feminina", obra que redefiniu o papel da mulher na época (Chrisler et al., 2013). Embora a reparação financeira não tenha sido conquistada, a partir desse evento simbólico, a APA organizou uma força tarefa que levou a criação em 1973 da divisão 35 (Sociedade pela Psicologia da Mulher), reconhecendo e institucionalizando o que agora é referido como psicologia feminista. Desde então, a psicologia norte-americana tem se dedicado a reverter os danos causados pelo estigma que até então ajudou a perpetuar revisando suas teorias e práticas (por exemplo, APA, 1975); uma tarefa longe de estar concluída (Hegarty \& Buechel, 2006).

No Brasil, os instrumentos empregados para avaliação psicológica são dispostos pela resolução do Conselho Federal de Psicologia (CFP, 2003b) número 002 de 2003. A resolução estabelece um sistema de avaliação por pares dos diferentes instrumentos disponíveis no país (SATEPSI), condicionando o seu uso profissional a aprovação prévia. Essa avaliação privilegia critérios técnicos, ou seja, evidência de validade e fidedignidade em estudos que confirmem as propriedades psicométricas dos instrumentos (Costa \& Nardi, 2013). Um dos testes aprovados 
na presente data é a Escala de Personalidade de Comrey (Comrey Preference Schedule, CPS). Originalmente publicada em 1970 pelo psicólogo norte-americano Andrew Comrey (Comrey, 1970), sua primeira versão brasileira foi publicada em 1973 (Rodrigues, 1979). Revisada em 2003, encontra-se agora na terceira edição (Costa, 2009). Trata-se de um teste que enfoca a avaliação "e descrição da personalidade "normal' . . mas pode mostrar-se útil na identificação de problemas de ordem psiquiátrica ou que requeiram intervenções psicoterápicas" (Costa, 2009 , p. 15). O instrumento é composto por 100 afirmativas distribuídas em 10 subescalas, voltadas à avaliação de diferentes fatores de personalidade. Cada afirmativa é avaliada em uma escala de 7 pontos, variando de "nunca (certamente não)" até "sempre (certamente sim)". A média das respostas nos itens que formam cada subescala é interpretada por um eixo de valores que direciona os extremos de cada fator. Dentre as subescalas, encontra-se a de Masculinidade e Feminilidade (M). A seu respeito, o autor afirma que "indivíduos com escores altos nesse fator disseram ser 'fortes', teimosos, e durões, que não se impressionam com cenas violentas, suportam vulgaridades e que não choram facilmente, nem demonstram interesse em histórias românticas e de amor" (p. 64). Afirma ainda que "aqueles com escores baixos choram com facilidade, perturbam-se com a visão de insetos e répteis e demonstraram interesses em histórias românicas" (p. 64).

Embora o autor da revisão expresse que o CPS não visa à identificação da hetero ou homossexualidade, também afirma que "a incidência de alguns valores nas faixas extremas, superiores ou inferiores, aponta a possibilidade de comprometimentos patológicos de conduta social" (p. 75). No entanto, o autor do instrumento original afirma que "altos escores na escala $\mathrm{M}$ mostraram-se associados estatisticamente com mulheres com [sic] homossexualidade e em homens com diagnóstico de personalidade esquizoide e problemas com a lei" (Comrey, 2008 p. 131), ele afirma ainda que escores muito baixos nos homens "é sugestivo de uma falha no desenvolvimento da identidade masculina normal.
Nas mulheres, sugere assertividade insuficiente para um ajuste eficaz" (p. 132). Alguns exemplos de itens da escala são: é difícil me fazer chorar; é tolice perder tempo pensando em amor e romance; insetos grandes e répteis me perturbam; pegaria uma cobra não venenosa com as mãos desprotegidas; situações grosseiras e vulgares me desagradam. Esse é um instrumento, no entanto, largamente utilizado no contexto de seleção de pessoal, especialmente em concursos públicos (Pereira \& Bandeira, 2009).

A pesquisa psicológica compreende hoje que esse tipo de instrumento está avaliando características socialmente consideradas masculinas e femininas expressas, sobretudo pelas preferências de homens e mulheres na época de sua criação (Lippa \& Connelly, 1990). O próprio autor do CPS, reconhecendo essa tendência, afirmou recentemente que com a publicação da versão revisada do instrumento em 1994, o nome da escala $\mathrm{M}$ foi alterada de "Masculinidade $v s$. Feminilidade" para "Resistência Mental vs. Sensibilidade" (Comrey, 2008, p. 132). Considerar que o CPS avalia um atributo intrínseco à masculinidade e à feminilidade, como no caso brasileiro, não é apenas um equívoco teórico. Do ponto de vista da igualdade de gênero, o instrumento apresenta graves implicações éticas. Essas implicações contradizem a visão do CFP que vem promovendo o debate acerca dos direitos das mulheres, além da valorização do protagonismo feminino na sociedade e a defesa da sua cidadania plena (CFP, 2013a). Contradizem ainda o recente foco do Conselho na luta pela construção da igualdade de gênero não apenas entre homens e mulheres, mas também entre pessoas cis e trans (CFP, s.d.). Portanto, o endosso desse instrumento pela psicologia brasileira no contexto atual é paradoxal.

A partir da análise crítica da versão brasileira da Escala de Personalidade de Comrey (CPS; Costa, 2009), o objetivo deste estudo é recuperar o tratamento histórico que a psicologia feminista deu às ideias de sexo e gênero e seus desdobramentos. Além disso, a partir das discussões contemporâneas nessa área, pretende apontar para uma concepção de gênero autodesignada, não essencialista, pluralista e não patológica. Por 
fim, visa a analisar como a psicologia enquanto instituição sustenta, no contexto contemporâneo brasileiro, o CPS como medida psicológica válida em paralelo, contraditoriamente, com a defesa da igualdade de gênero.

Este estudo se configura como uma revisão crítica da literatura psicológica sobre a avaliação do sexo e do gênero (Von Hohendorff, 2014). A análise privilegiará a produção científica da psicologia feminista anglo-saxã. Essa escolha se justifica uma vez que foi a psicologia feminista que ofereceu uma crítica consistente à avaliação do gênero a partir do contexto de onde ela emergiu. Com essa escolha não se está ignorando a existência de contribuições de outras áreas do conhecimento como a sociologia, a história, a filosofia e do ativismo político, uma vez que se entende que existe uma inter-relação entre esses campos nos estudos de gênero.

A perspectiva de análise adotada é a da ontologia histórica de Ian Hacking (2004). Essa perspectiva reconhece que os objetos de estudo das ciências humanas são dinâmicos e interativos. Ao contrário das rochas, por exemplo, que não se importam em ser classificadas como tal, quando as pessoas se tornam cientes da forma como são classificadas, modificam a sua conduta, o que requer novas classificações, as quais gerarão novas condutas, num efeito retroalimentador ao longo da história do conhecimento. Essa interação entre o classificado e classificação no contexto das ciências humanas é chamada de looping effect of human kinds (Hacking, 1995). A perspectiva da ontologia histórica reconhece ainda a influência das relações de poder nesse processo, por exemplo, através das instituições criadas em torno das pessoas classificadas destinadas ao estudo, tratamento, encarceramento, e estratégias de resistência por elas suscitadas (Hacking, 2007). Um exemplo desse processo ocorreu no caso da ideia de homossexualidade que foi medicalizada e criminalizada por especialistas no final do século XIX. A partir dos anos 1960, o movimento gay retorna aos sujeitos o controle da classificação aplicada sobre eles, significando-a de forma positiva.

A perspectiva da ontologia histórica compreende também que o tipo de classificação re- alizado nas ciências humanas e da saúde é prescritivo e não pode ser feito de maneira neutra, já que opera com categorias como normal/anormal, bom/mal, saudável/patológico, esperado/não esperado, belo/feio, etc. (Hacking, 2004). Isso aponta para a implicação ética dos produtores de conhecimento em relação à subjetividade das pessoas classificadas. Ian Hacking, autor dessa perspectiva, recorre à noção de ética na obra de Michel Foucault como horizonte para sua proposta de análise. Para Foucault (2004), a ética é entendida simplesmente como a prática reflexiva da liberdade. Liberdade entendida como a possibilidade de os indivíduos atuarem ativamente na construção de sua subjetividade. Portanto, o horizonte ético da perspectiva da ontologia histórica é a do processo de classificação reconhecer e possibilitar espaço para a autoinvenção e reinvenção por parte dos sujeitos classificados (Hacking, 2004). Esse componente ético é particularmente relevante para a discussão presente no final desse estudo onde são apresentadas alternativas à avaliação de gênero, repensando o papel da psicologia tendo em vista a maximização da liberdade dos sujeitos.

O exame da diferença supostamente natural entre homens e mulheres é uma ideia relativamente recente. O historiador Thomas Laqueur (2001) demostrou que ela emergiu no pensamento ocidental no século XVIII diante de interesses políticos que encontraram no estudo dessas diferenças uma justificativa para manutenção da hierarquia masculina na organização da sociedade.

O modelo científico predominante até o século XVIII era o modelo do sexo único. Esse modelo, oriundo da medicina greco/romana, entendia as diferenças anatômicas percebidas nos órgãos genitais como diferentes graus de uma mesma espécie. $\mathrm{O}$ canal vaginal era visto como um pênis voltado para dentro que com a força e a intensidade do "calor vital", evoluiria até a completude anatômica. O modelo do sexo único seria de um mundo "onde as fronteiras entre masculino e feminino são de grau e não de espécie, e onde os órgãos reprodutivos são apenas um sinal entre muitos do lugar do corpo . .." (Laqueur, 2001, p. 41). 
No modelo que emergiu em seguida, homens e mulheres teriam propriedades que se suponham específicas e necessárias. Uma das ciências que se dedicava ao estudo nesse modelo era a frenologia, a qual afirmava que o formato do crânio das mulheres evidenciava subdesenvolvimento de regiões cerebrais necessárias para o sucesso intelectual, ao passo que mostrava desenvolvidas as regiões relacionadas à maternidade (Staum, 2003). Os sujeitos, que até então eram avaliados por suas atitudes religiosas ou pelos valores aristocráticos, passam a ser avaliados pela conformidade à sua "natureza" biológica e, posteriormente, psicológica (Fausto-Sterling, 2008; Foucault, 1998; Katz, 1996). Isto é, o conjunto de ideias oriundas da psicologia do senso comum usadas na época para justificar qualidades que seriam desejáveis a mulheres e homens foi ganhando respaldo na medida em que essas concepções foram incorporadas às ciências que se consolidavam na época.

A psicologia científica nasce no final do século XIX, preocupada entre outras coisas, com essas diferenças. Exemplos são as pesquisas sobre a maior variabilidade intelectual masculina, sobre o instinto materno e sua relação com a chamada natureza feminina (Shields, 1982). Essas questões eram examinadas sob influência da perspectiva darwinista. Em "A Descendência do Homem e Seleção Sexual" (1871/1933), Darwin oferece uma hipótese para explicar sua observação de que em muitas espécies somente os machos desenvolveriam maior variedade de características sexuais secundárias (a cauda dos pavões, por exemplo), ao contrário das fêmeas. A variabilidade era aceita como um mecanismo de processo evolutivo (sobrevivência do mais apto e transmissão das variações mais adaptativas), e logo se convencionou que se tratava de um atributo positivo legitimado pela teoria evolucionista. Dessa forma, a maior variabilidade dos machos se tornou uma explicação conveniente para um grande número de diferenças entres mulheres e homens da época, não apenas em atributos físicos, mas também mentais (Shields, 1975).

Segundo a hipótese da variabilidade, mesmo que nos asilos do período se encontrassem mais homens do que mulheres com problemas físicos e mentais, isso era compensado por haver na sociedade mais homens com valores considerados positivos, como genialidade e fama (Shields, 1982). Uma das evidências para tal hipótese era fornecida por estudos que compilavam pessoas ilustres e traçavam sua genealogia, constatando pouca prevalência de mulheres. Francis Galton (1869), sobrinho de Darwin e precursor da avaliação psicológica, conduziu pesquisas a esse respeito. A ideia era de que atributos individuais, como a maior inteligência e força física atribuída aos homens, explicariam a adaptação ao ambiente que culminariam na eminência pessoal, sendo esses atributos hereditários. Raras eram as referências de que o contexto, não a hereditariedade, explicaria a baixa prevalência de mulheres nesses estudos (Shields, 1975).

Com o desenvolvimento dos testes de inteligência (chamados testes mentais na época), tal perspectiva ganhou impulso. Diferenças eram constatadas em tarefas como associação de ideias, preferência por cores, caligrafia, memorização de imagens, velocidade de leitura, capacidade para o cuidado de crianças pequenas (Morawski, 1985). Nos Estados Unidos, por exemplo, onde a pesquisa psicológica se desenvolvia amplamente, esse viés que privilegiava os homens se instalou com força (Minton, 2000). Diferenças entre homens e mulheres, constatadas na pesquisa psicológica, automaticamente se convertiam em expectativas em relação ao desempenho de papeis sociais. Dessa forma, a psicologia de então fez com que a hipótese da menor variabilidade não servisse apenas de explicação para o estatuto social desfavorecido das mulheres, mas de sua justificativa (Shields, 1975). Stanley Hall (1904), entre outros, acreditava, por exemplo, que era imperativo educar as meninas separadamente dos meninos, de forma que fossem preparadas para a maternidade e o trabalho doméstico, algo considerado inato à condição de mulher.

Esse pensamento começa a ser disputado quando as primeiras mulheres ingressantes na carreira da pesquisa psicológica publicam seus estudos (Minton, 2000). Helen Thompson Woolley revisou diversas pesquisas que investiga- 
vam as diferenças entre mulheres e homens em habilidades motoras e sensoriais (Thompson, 1903). Ela conclui que essas diferenças eram demasiadamente pequenas para serem consideradas significativas, embora uma parte dos estudos favorecessem as mulheres. A sua conclusão era de que

as diferenças sexuais em termos psicológicos parecem ser, em grande parte, devidas não a diferença de capacidade média, nem no tipo de atividade mental, mas nas influências sociais exercidas sobre o indivíduo em desenvolvimento desde a primeira infância à idade adulta. (p. 182)

No entanto, foi Leta Stetter Hollingworth quem realizou pesquisas que desafiaram a visão prevalente a respeito da menor variabilidade $-\mathrm{e}$, portanto, inferioridade - feminina (Silverman, 1989). Questionando uma das ideias centrais da época, a autora também demonstrou que a população com deficiência intelectual era semelhante entre mulheres e homens. Ao analisar a idade dos moradores nas instituições da cidade de Nova York, Hollingworth (1914) constatou que, embora houvesse maior número de meninos do que de meninas, o número de mulheres internas aumentava a ponto de se equivaler ao de homens conforme a sua idade avançava. Para Hollingworth, não havia explicações determinísticas para esse fenômeno. Sua hipótese era de que deficiências intelectuais entre as mulheres eram invisibilizadas em função do seu papel social. Por não ser esperada das mulheres habilidade mental na época, elas não eram precocemente avaliadas. Portanto, só ingressavam nas instituições quando, graças à idade, não serviam mais para as tarefas ditas femininas:

As mulheres têm sido e são uma classe dependente e não competitiva, e quando possuem alguma diminuição de capacidade podem mais facilmente sobreviver fora das instituições, uma vez que para manter-se no meio social elas não têm que competir mentalmente entre si, como fazem os homens. (p. 515)

Woolley e Hollingworth ajudaram a demonstrar que as diferenças entre mulheres e homens cristalizadas pelo pensamento psicoló- gico da época eram reféns de um androcentrismo institucionalizado, isto é, um viés que analisava o resultado das pesquisas a partir de uma visão que privilegiava os homens atribuindo a eles valores socialmente positivos e tidos como inatos. Embora suas obras sejam reconhecidas hoje como precursoras da psicologia feminista, foram largamente ignoradas (Silverman, 1989). Amparado pela psicologia da época, era negado às mulheres acesso a diversas instituições como trabalho, educação superior e ao sufrágio. Além disso, eram classificadas como desajustadas (histéricas) quando fugiam do papel social delas esperado, como a maternidade, o trabalho doméstico e o recato sexual (Gilman, 1985).

Cabe ressaltar que a diferença entre homens e mulheres não era apenas avaliada em relação à adaptação social, mas também, à sexual. Em 1869, o jornalista húngaro Karol Maria Kertbeny criou os termos homossexual e homossexualidade, em um texto contrário ao código penal Prussiano que condenava esse tipo de conduta. Mais tarde, o termo foi apropriado pelo psiquiatra Krafft-Ebing na sua teoria dos desvios sexuais, associando homossexualidade à patologia (1886/2011). Em Psychopathia Sexualis, o autor examinava práticas sexuais a partir da perspectiva darwinista emergente de que todo comportamento sexual que não visava à procriação era desadaptativo. Krafft-Ebing também foi um dos pioneiros a documentar casos de pessoas que gostariam de viver ou já viviam como o sexo diferente do designado ao nascimento. $\mathrm{Na}$ época, no entanto, o comportamento sexual e aquilo que é hoje é denominado identidade de gênero não eram tidos como categorias distintas (Drescher, 2010). Isso era visível tanto nas teorias que afirmavam que homossexuais teriam uma "alma feminina" em um corpo masculino, quanto na hipótese freudiana do desenvolvimento sexual "invertido" (Freud, 1920/2011), ou na noção genérica de invertidos sexuais propagada por Krafft-Ebbing e pelo sexólogo Havelock Ellis (1927/2013). Magnus Hirschfeld é creditado como o precursor, entre os anos 1910 e 1920, da distinção entre o desejo por pessoas do mesmo sexo e o desejo de viver como alguém de um sexo diferente do designado ao nascimento, 
que ele dava o nome de transvestismo (Drescher, Cohen-Kettenis, \& Winter, 2012). No entanto, como veremos a seguir, tais distinções só foram amplamente aceitas posteriormente, graças ao trabalho de Henry Benjamin e John Money. Assim, baseados nas teorias da época, até a segunda metade do século XX, profissionais da psicologia e da psiquiatria ofereciam toda sorte de terapias corretivas das variações sexuais e de gênero (Drescher, 2010).

Com a popularização da avaliação psicológica no início do século XX, foram desenvolvidos inúmeros instrumentos para medir uma imensa gama de aptidões: verbais, matemáticas, entre outras. As pesquisas sobre as diferenças entre homens e mulheres também aumentava, mas envolta em grande confusão já que, no geral, os estudos não chegavam a uma conclusão que favorecesse claramente a um ou outro (Morawski, 1985). Foram Lewis Terman e Catherine Miles que, em 1936, oferecem uma solução para esse impasse. Analisando os diversos testes disponíveis na época, os autores selecionaram apenas os itens em que homens e mulheres diferiam para formar um novo instrumento capaz de analisar não mais a diferença entre homens e mulheres em um dito teste, mas as diferenças entre a "masculinidade" e a "feminilidade" no padrão de resposta. Ou seja, uma medida "do sexo psicológico" onde as diferenças entre homens e mulheres encontradas na pesquisa psicológica anterior, estabeleceriam o que foi tomado como o padrão de feminilidade e masculinidade.

Para reduzir a possibilidade de influência na resposta, o instrumento foi genericamente denominado de Attitude Interest Analysis Survey (AIAS; Terman \& Miles, 1936). Nesse instrumento, masculinidade e a feminilidade eram compreendidas como um construto bipolar e unifatorial. Isso significa dizer que masculinidade e a feminilidade eram polos opostos de um único continuo e, no caso do teste de Terman e Miles (1936), isso equivale a diferentes respostas nos 456 itens de associação de palavra, atitudes em relação aos sentimentos, interesses e opiniões divididos em sete subescalas. $\mathrm{O}$ escore de feminilidade era pontuado a partir da resposta negativa a perguntas como: gostar andar de bicicleta, brincar com cobras, ver uma flor ou uma estrela em uma mancha de tinta, e o de masculinidade, por sua vez, em respostas como: afirmar ver um morcego na mesma mancha ou desgostar de estrangeiros, mulheres inteligentes e de dançar. É notável que a definição de feminilidade do teste é refém da visão androcêntrica que provinha dos primeiros estudos nessa área: "Submissão, docilidade, constância de propósito inferior, e uma falta geral de agressividade reflete suas tendências conativas mais fracas" (Terman \& Miles, 1936, p. 2).

$\mathrm{Na}$ esteira da proposta original de Terman e Miles, muitos testes foram criados para avaliar exclusivamente a masculinidade e a feminilidade, ou avaliar esse fator dentro de um conjunto maior de características. Uma dessas escalas é o Guilford-Zimmerman Temperament Survey (Guilford \& Zimmerman, 1949), um teste de personalidade que inclui uma escala de masculinidade e a feminilidade que serviu de inspiração para a escala M do CPS (Comrey, 2008, p. 117). Outro exemplo é o Minnesota Multiphasic Personality Inventory (MMPI; Hathaway \& McKinley, 1940). Esse instrumento foi desenvolvido para o contexto da psicologia clínica com o objetivo de mensurar traços associados à psicopatologia e desordens psicológicas. O MMPI possui uma escala de masculinidade e feminilidade inspirada na medida de Terman e Miles, porém com a maioria de itens desenvolvida especificamente para esse instrumento. No entanto, ao invés de eleger itens que distinguiriam homens de mulheres como a escala de Terman e Miler, o teste utiliza especialmente itens que distinguiriam homossexuais de heterossexuais (Shields \& Dicicco, 2011).

No contexto norte americano as teorias psicanalíticas ganhavam fôlego e com elas a compreensão de que a diferença sexual era um atributo psíquico central para a personalidade, não acessível à consciência (o que justificava uma avaliação externa), e que seguiria um desenvolvimento tido como normal (Morawski, 1985). Ou seja, uma pessoa emocionalmente saudável seria aquela que teve o sexo feminino atribuído ao nascer, identificada como mulher, conformada e se comportando de acordo com as expec- 
tativas sociais apropriadas para a personalidade feminina da época e, heterossexual. Na assunção da época, homens "femininos" e mulheres "masculinas" eram automaticamente considerados invertidos sexuais. Portanto, esse tipo de avaliação de gênero tinha como intuito avaliar essas supostas incongruências (Shields \& Dicicco, 2011).

A $6^{a}$ edição da Classificação Internacional de Doenças (CID), publicada em 1948, foi a primeira publicação da Organização Mundial de Saúde a incluir uma classificação de doenças mentais. Seguindo as tendências da época, as variações de gênero e de sexualidade (homossexualidade e transvestismo) eram consideradas fenômenos similares e apareciam tanto na CID-6, quanto na edição seguinte de 1952 (CID-7), como termos de inclusão para o diagnóstico de desvios sexuais, os quais eram classificados como integrantes de uma personalidade patológica (Drescher et al., 2012). A Associação Norte-Americana de Psiquiatria, seguindo as mesmas tendências, publica em 1952 a primeira edição do seu manual (DSM-I) listando tudo o que a psiquiatria considerava como doença mental na época. Nesse manual, os desvios sexuais, dentre eles a homossexualidade e o transvestismo, também eram classificados como distúrbio de personalidade.

No entanto, outra tendência de estudo das variações sexuais e de gênero começa a questionar a visão prevalente. Ganham influência nessa época estudos, como o da antropóloga Margareat Mead (1935/2011), que mostravam que homens e mulheres têm papeis sociais e sexuais completamente distintos em outras culturas. É também dessa época o trabalho de Alfred Kinsey, Pomeroy e Martin, que, em 1948, publicam seu livro sobre o comportamento sexual dos homens americanos constatando que experiências homossexuais eram relativamente comuns nos Estados Unidos. São da mesma época os trabalhos de Evelyn Hooker $(1957,1958)$ que conduziu o primeiro estudo comparando amostras não clínicas de homossexuais e heterossexuais. Hooker concluiu que a homossexualidade não constituía uma entidade clínica e não deveria estar associada à psicopatologia. Além disso, o trabalho dessa autora questionou o uso da avaliação psicológica para identificar a orientação sexual, afirmando que "sua validade duvidosa torna o seu valor questionável” (1958, p. 51).

Na mesma época, John Money publica seus estudos a respeito de crianças nascidas com condições intersexuais (Money, Hampson, \& Hampson, 1955, 1957). Analisando casos de procedimentos médicos de designação sexual em crianças nascidas com genitália ambígua, Money acreditava que a atitudes dos pais teriam um forte efeito sobre a aceitação da criança na categoria clinicamente atribuída. Money foi pioneiro em fazer a distinção entre sexo e gênero, teorizando que o senso de ser homem ou mulher era adquirido principalmente por fatores ambientais. Para Money, havia uma diferença entre (a) os fatores anatômicos e fisiológicos, ou seja, o "sexo" cromossômico, hormonal, gônadas, e a genitália externa e interna; (b) a socialização de gênero na primeira infância; e (c) as características psicológicas - o papel social de gênero adquiridas através dessa socialização. Posteriormente, Money diferenciou identidade de gênero - o senso privado - do papel social de gênero - a expressão pública da identidade de gênero (Money \& Ehrhardt, 1972).

Em meados dos anos 1960, na esteira da obra de Money surgem as primeiras clínicas oferecendo procedimentos de modificação genital para adultos que procuravam esse tratamento. Embora as experimentações com essas cirurgias tenham começado nos anos 1920 e 1930, a partir da ideia de que o gênero se fixava precocemente e de que os esforços para mudá-lo eram infrutíferos, as técnicas médicas de transformação corporal se mostraram uma alternativa terapêutica aceitável. Harry Benjamin (1966) é creditado como o popularizador do termo transexual e responsável pela sensibilização sobre a necessidade da atenção à saúde das pessoas trans, enquanto a psiquiatria e a medicina da época as consideravam como homossexuais confusos, invertidos, e esquizofrênicos (Drescher, 2010). Para Benjamin, por exemplo, uma mulher transexual seria uma pessoa do gênero feminino "presa" em um corpo do sexo masculino, sendo que a única alternativa terapêutica seria o tratamento hormonal e cirúrgico com objetivo de realizar a "transição" para o "outro sexo" (homem para mulher 
- ou mulher para homem). Benjamin inaugurou a distinção entre transvestismo e transexualidade, misturadas até então, mostrando que no primeiro caso não estava em jogo o desejo de mudança corporal e de afirmação da identidade. Embora algumas dessas noções tenham se modificado recentemente, como veremos a seguir, graças a Benjamin, se afirmou cientificamente a ideia de que as pessoas trans não deveriam ser sujeitas a terapias conversivas, consolidando a terapêutica que é utilizada até hoje (Coleman et al., 2012).

$\mathrm{O}$ conceito de gênero teve grande impacto na forma de se conceber o determinismo biológico e psicológico impulsionando uma nova onda do feminismo, inclusive na psicologia (por exemplo, Unger, 1979). A ideia de que o sexo seria algo biológico e gênero algo social ajudou a enfrentar as crenças de que haveria nesse âmbito uma equivalência entre natureza e cultura. $\mathrm{Ou}$ seja, se consolida a compressão de que boa parte das diferenças atribuídas a homens e mulheres se devia à socialização. Em outras palavras, as pessoas eram ensinadas a terem características masculinas e femininas e a se identificarem como homens e mulheres. A pesquisa psicológica anterior começa a ser compreendida enquanto estudos sobre o gênero, uma categoria criada em referência aos corpos biológicos, mas não determinada por eles.

Essas transformações teóricas e políticas podem ser percebidas nos manuais médicos da época. A ideia de que as variações de sexualidade de gênero não constituíam um desvio de personalidade aparecem pela primeira vez na CID-8 (1965), em diagnósticos separados -homossexualidade e transvestismo -, sem apresentar definições. O DSM II é publicado em 1968 e mantém a mesma separação e nomenclatura. $\mathrm{Na}$ CID-9, de 1975, foi adicionada a categoria transexualismo para dar conta das novas estratégias de tratamento apresentadas nas décadas anteriores. A homossexualidade ainda aparecia como um distúrbio na CID-9, no entanto, influenciada principalmente pelo ativismo político, a sétima impressão do DSM-II, em 1974, já não listava a homossexualidade como uma categoria de desordem. Nesse manual, o diagnóstico anterior foi substituído pelo de "distúrbio de orientação sexual", diagnosticando a homossexualidade como uma doença apenas nos casos em que o indivíduo sinta mal-estar em relação a ela e queira mudar (Drescher, 2010).

Essas novas visões também servem de estopim para uma série de movimentos na sociedade civil e nas sociedades de psicologia que se afastam de um modelo que anteriormente buscava justificar diferenças a partir de um viés excludente para as pesquisas que buscam, por exemplo, a gênese da violência de gênero, o sexismo (Eagly, Eaton, Rose, Riger, \& McHugh, 2012). De forma similar com o que ocorreu em relação ao sexismo, no momento em que a homossexualidade por si só deixa de ser um problema psicológico, a atenção nesse campo recai sobre aqueles que a consideram um desvio. George Weinberg publica, em 1972, Society and the Healthy Homosexual, popularizando o termo homofobia. Sexismo e homofobia se consolidam como pautas da análise e intervenção acadêmicas e bandeiras dos movimentos feminista e homossexual.

Embora inconsistências fossem ocasionalmente encontradas, o modelo de avaliação da masculinidade e feminilidade proposto por Terman e Miles (1936) permaneceu como referência por mais de três décadas. Essa técnica sofreu suas maiores críticas apenas em 1973 com trabalho de Anne Constantinople. Essa pesquisadora foi a primeira a reunir evidências de que esse tipo de avaliação não possuía suporte teórico, atacando a ideia de que os traços avaliados seriam duradouros, relacionados com diferenças anatômicas, experiências primárias e que serviriam para distinguir homens de mulheres em termos de atitudes e comportamentos. Segundo Constantinople (1973), o fato dos estudos existentes evidenciarem que homens e mulheres não respondiam da forma esperada, essas escalas não deveria servir para rotulá-los como desviantes, invertidos ou em conflito, mas para ressaltar os problemas do construto em questão.

Constantinople (1973) sugeriu que não existiria única dimensão bipolar que envolveria em um extremo a masculinidade e no outro a feminilidade, que não era afetada pelo desenvolvimento, e nem teria relação com marcadores socio- 
demográficos. Pelo contrário, muitos homens e mulheres apresentavam igualmente características associadas à masculinidade e feminilidade, características que normalmente variavam ao longo do ciclo vital e de acordo com classe social e cultura. Além disso, a literatura não apoiava a ideia de que homens homossexuais teriam funcionamento psíquico equivalente a mulheres femininas e mulheres lésbicas aos homens masculinos. Dessa forma, a ideia de inversão sexual também deveria ser revista. Para Constantinople, essas escalas mediam

a expectativa da pessoa testada de como ela deveria responder a questões do tipo "eu gostaria de dirigir um carro de corrida". Esse deveria responder é baseado no estereótipo do papel da mulher derivado do senso comum e dos dados que são provavelmente 20 anos mais velhos do que a pessoa que está respondendo ao teste. (Constantinople, 1973, p. 403)

Diante dos problemas desse tipo de medida, Constantinople perguntava: "se as escalas M-F refletem um número de subtraços como agressividade, sensitividade, autoconfiança, etc., há algum ganho em combinar essas medidas a partir do que seria mais característico a homens e mulheres?" (1973, p. 405). Não foi exatamente o que ocorreu.

Em 1974, Sandra Bem introduziu o Bem Sex Role Inventory (BSRI) como uma nova forma de medir e a masculinidade e feminilidade. O BSRI foi construído na época da emergência da psicologia cognitiva e das teorias do processamento da informação, a partir da ideia de tipificação sexual, ou seja, a partir da ideia de que as pessoas internalizam normas e comportamentos socialmente desejáveis para homens e mulheres e passam a operar a partir deles (Bem, 1974). No BSRI, o respondente é solicitado a descrever-se em 60 características de personalidade em uma escala de Likert de 7 pontos $(1=$ discordo, $7=$ concordo). Essas características foram classificadas como masculinas, femininas e neutras a partir do que era mais desejável na sociedade norte-americana da época. Dentre as características femininas estão, por exemplo, compaixão, o amor a crianças, e a ternura, dentre as masculi- nas a assertividade, a personalidade forte, e a capacidade de liderança, e, dentre as consideradas neutras, ser adaptável e convencional. A novidade introduzida por Bem diz respeito à forma de avaliação do teste. Uma pessoa com taxas elevadas em ambas as dimensões (masculinidade e feminilidade) era classificada como "andróginas"; baixa em ambas, "indiferenciada"; e alta em uma dimensão, mas baixa em outra, sexualmente tipificada como "masculina" ou "feminina" (Bem, 1977). A medida de Bem não mais prescrevia a correspondência entre o "sexo biológico" e características atribuídas a homens e mulheres, acabando totalmente com a ideia de desvio e inversão sexual. No modelo de Bem, na verdade, as pessoas melhores ajustadas seriam aquelas com valores equivalentes de masculinidade e feminilidade (hipótese da androginia). Esses indivíduos "balanceados", não seriam sexualmente tipificados e, portanto, seriam mais flexíveis nos seus conceitos e comportamentos, e psicologicamente mais saudáveis (Bem, 1974, p. 162).

Embora as implicações da escala de Bem tenham sido libertadoras para época, especialmente em relação à ideia de androgenia, diversas críticas sugiram a essa abordagem. Uma delas veio das pesquisas que se dedicaram a estudar a socialização, que teve como expoente Alice Eagly (1987). Essa perspectiva teórica busca compreender de que forma a sociedade concebeu, por exemplo, que as mulheres deveriam ter compaixão e os homens capacidade de liderança e de que forma as pessoas seriam ensinadas a atuar de acordo com essas características. Para Eagly, tanto homens quanto mulheres podem ter "compaixão" ou "capacidade de liderança" desde que tenham o suporte social que permita que eles exerçam essas capacidades. O que essa teoria aponta é que existe uma pressão da sociedade, de acordo com cada cultura e contexto histórico, dividindo de maneira desigual o que é esperado para homens e mulheres, e fazendo com que eles e elas se adaptem a essa divisão ao longo do seu desenvolvimento.

A partir desse modelo, muitos experimentos mostraram como crianças pequenas são "ensinadas" a serem homens e mulheres, de maneira muitas vezes pouco perceptível. Em um estudo 
clássico, foi solicitado que mães interagissem com bebês menores de um ano. Se o bebê fosse chamado de menina, mais frequentemente era oferecida uma boneca. Se o mesmo bebê fosse chamado de menino, com mais frequência era oferecido um trem (Will, Self, \& Datan, 1976). Em outro experimento, Condry e Condry (1976) mostraram a estudantes universitários um vídeo com as reações de um bebê ao receber um brinquedo. Se fosse informado que o bebê era um menino, os estudantes classificavam o seu comportamento com mais frequência como sendo raiva. Por outro lado, se fosse informado que o mesmo bebê era uma menina, os estudantes classificavam o mesmo comportamento como medo. Outros estudos mostravam ainda como os pais reagiam negativamente quando seus filhos meninos brincavam com bonecas ou se vestiam com roupas de menina, e vice versa (Langlois \& Downs, 1980).

Em princípio, a teoria do papel social não invalida a posição de Bem de que as pessoas se identificariam com os papeis de gênero disponíveis numa dada cultura e passariam a atuar a partir deles. No entanto, essa teoria aponta que as características não são atribuídas a homens e mulheres aleatoriamente, já que existe uma dinâmica social que fomenta a diferença nessa atribuição. A conclusão a respeito das pesquisas sobre a socialização é de que quando a distribuição dos papeis se tornar mais igualitária, boa parte da diferença detectada entre homens e mulheres vai desaparecer (Eagly, 1987). Desse modo, a teoria do papel social reconhece a psicologia como uma das instituições que promove a manutenção dos papeis gênero, e advoga que ela trabalhe na direção da correção das desigualdades e não o oposto. O uso do BSRI, nesse sentido, mesmo que reflita características de homens e mulheres em uma dada época, reforça e naturaliza, por exemplo, que é masculino e não feminino ter uma personalidade forte e, portanto, a desigualdade de gênero.

Outra perspectiva crítica em relação à proposta de Bem é a de Janet Spence (para uma revisão: Spence, 2011). A proposta de Spence afirma que o gênero é mais do que a adesão aos papeis sociais. Desde meados da década de 1980, Spen- ce sugeriu que no lugar de características e comportamentos tipicamente associados a homens e mulheres, a masculinidade e a feminilidade deveriam ser conceitualizadas como identidade de gênero. Para Spence, a maioria das pessoas tem segurança quanto a sua identidade de gênero e essa identidade se mantém segura mesmo quando não está de acordo com os padrões considerados aceitos. Por exemplo, embora possa fazer parte do que é socialmente esperado, uma pessoa pode ter uma clara identidade de gênero feminina apesar do fato de não ser mãe, se essa característica não fizer parte da sua definição particular do que é ser mulher.

Spence realizou uma série de experimentos para apoiar sua hipótese (Spence, 1993; Spence \& Buckner, 2000). Nesses experimentos ela pedia para que as pessoas avaliassem em duas escalas de cinco pontos o quanto masculinas e o quanto femininas elas achavam que eram. Ela então calculou a correlação entre essa autoavaliação com medidas externas de gênero, como BSRI. A auto avaliação da feminilidade foi alta e de masculinidade foi baixa nas pessoas que se identificavam como mulher e o contrário aconteceu com as pessoas identificadas como homens. Além disso, quase todas as correlações entre a autoavaliação e as outras medidas não foram significativas.

Mesmo que não seja articulada, a constância que as pessoas sentem em relação à sua identidade de gênero pode dar origem à ilusão de que todas as diferenças observáveis nas características e comportamentos de homens e mulheres contribuem para uma propriedade psicológica subjacente, masculinidade-feminilidade, que poderia ser avaliada a partir de suas supostas manifestações. (Spence, 1993, p. 634)

O resultado desses estudos, portanto, suporta a hipótese de que o mais importante na avaliação do gênero é autodesignação da identidade. Ou seja, as pessoas não estão enganadas quando dizem que são homens ou mulheres embora a psicologia e suas avaliações digam o contrário!

Por fim, a crítica mais contundente a proposta de avaliação no modelo do BSRI parece ter vindo do debate em relação às pessoas trans. 
A atenção à saúde dessas pessoas por meio de procedimentos de modificação corporal inaugurada por Henry Benjamin e cristalizada na CID-9 se institucionaliza ainda mais com a publicação do DSM-III, em 1980, no qual o transexualismo aparecia novamente como categoria diagnóstica. O DSM-III também marcou a vitória do movimento feminista com a remoção da categoria "histeria" que se mostrou não relevante clinicamente e discriminatória (Ussher, 2013). Com a publicação da CID-10 em 1990 e do DSM-IV em 1994, transexualismo é modificado para transtorno de identidade de gênero. Essa mudança reforça a ideia de Benjamin e de Money de que as pessoas trans sofreriam por terem algo como uma "alma" de um gênero presa em um corpo de outro. Nesse momento, apesar do debate corrente, a institucionalização do critério diagnóstico de transexualismo e, posteriormente, de transtorno de identidade de gênero foi liberadora tanto para as pessoas trans - uma vez que elas poderiam acessar mais facilmente os procedimentos de mudança corporal -, quanto para a clínica medica que não precisaria realizá-los de forma experimental ou clandestinamente (Drescher, 2010).

O estudo do BSRI com pessoas trans revelou dados interessantes evidenciando a existência de outras formas de construção do gênero. Por exemplo, estudos revelaram que mulheres trans não se identificavam completamente com as características associadas a mulheres cis (o mesmo em relação a homens trans e cis), diferindo inclusive entre si (Fleming, Jenkins \& Bugarin, 1980; Herman-Jeglińska, Grabowska \& Dulko, 2002). Além disso, as mesmas pesquisas começaram a mostrar que algumas pessoas trans não buscavam procedimentos de mudança corporal por rejeição à masculinidade ou à feminilidade, $\mathrm{e}$ outras simplesmente não os buscavam. Ou seja, reforçavam o ponto de vista de Spence: para algumas pessoas trans, a identidade de gênero era independente tanto do sexo designado ao nascimento quanto do que era socialmente esperado para homens e mulheres. E nesse caso, o BSRI falhava duplamente: primeiro por privilegiar a avaliação externa à identidade de gênero, e, segundo, por operar através de um modelo binário (masculino/homem e/ou feminina/mulher) quando as evidências sugeriam outras possibilidades.

Muehlenhard e Peterson (2011) relataram em seu artigo um caso anedótico exemplar. Em uma banca de dissertação, uma aluna que havia comparado homens e mulheres foi questionada por dois professores. Um deles perguntou: "você avaliou os cromossomos, perguntou sobre os genitais?" Com a resposta negativa da estudante o professor afirmou: "então você estava pesquisando diferenças de gênero e não sexuais". Já o outro membro da banca indagou: "Você mediu a masculinidade e a feminilidade? Você usou o BSRI?" A estudante outra vez disse que não. "Então você investigou diferenças sexuais e não de gênero!" O caso de Muehlenhard e Peterson revela o quanto a psicologia ainda estava atrelada ao modelo da diferença entre sexo (biológico) e gênero (social) em termos do binarismo homem/mulher. Modelo também presente no manejo clínico das pessoas trans, já que profissionais de saúde não as encorajavam a viverem abertamente como "trans", mas a fazerem uma passagem completa para o "sexo oposto" (Drescher, 2010).

Esse modelo começa a ser questionado com emergência de estudos mostrando que diferentes construções de gênero estão presentes em outros contextos culturais e históricos, inclusive na figura de um "terceiro sexo" (Herdt, 1996). Além disso, ganha força a ideia de que o gênero e a sexualidade são arenas diferentes da experiência humana e também de ativismo político. Nos anos de 1990, emerge no contexto norte-americano a categoria transgênero abarcando o conjunto de variação de gênero que inclui as pessoas trans, cross-dressers, drag queens e drag kings, e qualquer pessoa que transgrida o modelo do gênero binário, mesmo que não esteja disposta a se submeter aos procedimentos de mudança corporal (Davidson, 2007). Dessa forma, muitas pessoas trans começam a "sair do armário" para a cena pública, reinterpretando a sua experiência a partir da categoria transgênero (Valentine, 2007).

Foram de grande influência para esse movimento os apontamentos feitos por Suzanne Kessler (Kessler, 1990, 1998; Kessler \& McKeena, 1978). Acompanhando o manejo clínico de 
crianças intersexuais, Kessler questiona a posição de John Money de que a designação sexual influenciaria definitivamente a identidade de gênero futura. A sua justificava vinha do caso de alguns indivíduos intersexuais adultos onde a identidade de gênero não concorda com o sexo atribuído ao nascimento por profissionais da medicina e reforçado pela família através da educação das crianças. Esse gerenciamento médico dos casos de intersexualidade, perpetuaria a ideia de que autenticidade de gênero reside na "natureza do sexo", e não na sua atribuição, seja por parte dos médicos, da família, ou do próprio indivíduo. Para Kessler, nós fazemos uma atribuição de gênero cada vez que encontramos uma pessoa e isso independe de características biológicas. Por exemplo,

se é atribuída a designação "homem" a uma mulher trans, se está afirmando que ela ainda não fez a transição ou não fez direito. Por outro lado, se é atribuída a designação "mulher" para essa pessoa, significa que, para todos os efeitos, ela é uma mulher crível. (Kessler \& McKeena, 1978, p. 14)

Kessler propõe que a ambiguidade genital no caso das crianças intersex não era aceita como uma opção não porque ela estava ameaçando a vida da criança (esses casos dificilmente são urgências médicas), mas porque ela estava ameaçando a sua cultura. Os procedimentos médicos garantiriam a atribuição de apenas um dos dois sexos culturalmente aceitos (homem pênis, mulher - vagina). O sexo e o gênero não seriam então categorias distintas já que a noção social binária de gênero está implícita na tentativa de encontrar nos cromossomos, gônadas e genitália externa e interna o "verdadeiro sexo". "O não-normativo é convertido em normativo, e o estado normativo é considerado natural. A ambiguidade genital é sanada para obedecer a uma 'natural', isto é, culturalmente indiscutível, dicotomia de gênero" (Kessler, 1990, p. 25).

Quando a distinção entre sexo e gênero se torna menos importante, as pessoas que não se encaixavam nas categorias atribuídas ao nascimento, deixam de ser tratadas como indivíduos que supostamente nasceram com um defeito; ou seja, o problema também é remetido às catego- rias limitadas da sociedade (Kessler, 1998). Ou seja, as pessoas trans (e também intersex) não seriam doentes cuja única opção seria a reparação médica, mas sim indivíduos emocionalmente saudáveis cuja expressão de gênero foi limitada por expectativas sociais causadoras de sofrimento. Dessa forma, o modelo de transexualidade propagado por Benjamin também perde força. Existem pessoas que sempre se consideraram mulheres, mesmo tendo nascido com um pênis, assim como pessoas que sempre se consideraram homem, mesmo tendo nascido com vulva. Na nova concepção, essas pessoas não realizam uma "transição" para o "outro sexo", elas adequam o seu corpo e seus registros civis à sua identidade de gênero, a despeito do sexo designado ao nascimento. A categoria transgênero surge como alternativa ao antigo modelo médico, na tentativa de afirmar às variações de gênero como variações da normalidade. Essa nova visão sobre o gênero, une as bandeiras do movimento social, ampliando o foco da luta pela construção de igualdade de gênero entre mulheres e homens, na direção da igualdade entre pessoas cis e trans. O movimento de gays, lésbicas e bissexuais (LGB) passa a incluir as demandas pelos direitos civis das pessoas trans e intersex (LGBTI), e uma parte do movimento feminista que estava se preocupando cada vez mais com interseccionalidades como classe social, raça/ cor/etnia, também passa a englobar a pauta trans, em direção ao transfeminismo (por exemplo, Serano, 2007).

Muitas áreas do conhecimento começam a reformar suas teorias e práticas a partir daí. Não seria diferente com a psicologia, que ajudou a criar um modelo baseado na patologização das variações do gênero, com foco naquilo que "deu errado" e que, portanto, deve ser corrigido, para um modelo positivo de afirmação, com foco no estigma associado às variações de gênero e às disparidades de saúde decorrentes delas (Bockting, 2009). Reflexos dessas mudanças estão na publicação do DSM-5 que despatologiza a identidade e passa a classificar apenas a disforia (mal-estar) de gênero (Cohen-Kettenis \& Pfäfflin, 2010) e a proposta da CID-11, que visa à remoção dessa condição da lista de doenças 
mentais (Drescher et al., 2012). O esforço da pesquisa contemporânea tem sido o de ampliar o conceito de gênero de forma que dê conta da experiência tanto das pessoas cis quanto das pessoas trans, sem exotismo ou exclusão. Por exemplo, reconhecendo que não são apenas as pessoas trans que modificam seu corpo para afirmar o seu gênero: mulheres e homens cis utilizam próteses de silicone, fazem exercícios e usam hormônios para afirmar seu gênero.

Tate, Youssef, e Bettergarcia, (2014) elencaram cinco categorias que abrangem as ideias trabalhadas nesse artigo:

1. O sexo designado ao nascer (também chamado de designação sexual);

2. A identidade de gênero, ou a autodesignação enquanto homem, mulher, travesti, neutro, queer, ou mesmo sem gênero;

3. A adesão aos estereótipos culturalmente associados aos gêneros;

4. As expressões ou performance pública de gênero, através do uso de nome próprio, linguagem corporal e indumentária; e

5. Atitude em relação ao gênero, podendo ser favorável, ou não (sexismo e transfobia; ver também: Hill \& Willoughby, 2005). Essa divisão se mostra bastante útil do ponto de vista teórico. Do ponto de vista prático, no entanto, resolvendo o impasse da dissertação apresentada por Muehlenhard e Peterson (2011), bastam duas perguntas, a partir da autodesignação: como você foi designado/a ao nascer? E, como você se identifica atualmente?

Além disso, devem ser acrescentadas a essas, as ideias contemporâneas em relação à sexualidade (para uma revisão atual ver: Diamond, 2009). A orientação sexual tem sido usada para designar o desejo sexual independentemente dele se manifestar no comportamento. Por exemplo, uma mulher pode ter uma orientação homossexual e nunca ter se relacionado de fato com outra mulher. A identidade sexual refere-se à autodesignação enquanto lésbica / gay / bissexual / heterossexual. Tal como ocorre com a orientação sexual, as identidades nem sempre correspondem a padrões de comportamento. Um homem pode se considerar heterossexual e manter relações sexuais com outros homens. É o caso que fez emergir a categoria "homens que fazem sexo com outros homens" (HSH). Além disso, algumas pessoas, podem rejeitar os rótulos identitários tradicionais em favor de outros como queer, pansexual, assexual, etc. Por fim, se junta a essas, a atitude positiva ou negativa em relação à diversidade sexual (homo, bi e lesbofobia). Essas categorias não correspondem a conceitos nosográficos estáveis e são determinadas ou pelo informadas pelas dinâmicas sociais. Por exemplo, algumas pessoas podem nascer com um pênis, ter uma identidade de gênero feminina, e, em alguns casos, sentirem atração por homens, e, em outros, por mulheres; atração que pode variar em diferentes momentos da vida.

O objetivo desse artigo foi apresentar as diversas maneiras como a psicologia tratou a avaliação de gênero de forma a situar historicamente o instrumento CPS. Reconhecendo a influência das distorções causadas pelas expectativas preconceituosas da sociedade, a psicologia parte de um modelo que considerava natural as diferenças entre homens e mulheres para outro que reconhece o gênero dentro de um sistema complexo de relações de poder. Ou seja, a psicologia feminista ajudou a acrescentar uma dimensão social ao modelo determinístico das diferenças sexuais e de gênero, frequentemente utilizado como argumento contra a igualdade de direitos, mostrando que sexo e gênero não são fenômenos naturais e cósmicos, mas institucionais e históricos. A isonomia, ou seja, a igualdade entre homens e mulheres, é também fenômeno institucional e histórico. No entanto, no modelo da isonomia, o que está em jogo não é a imposição da homogeneidade (sexual e de gênero), mas o reconhecimento de grupos estigmatizados (inclusive por teorias que a psicologia ajudou a propagar), e que são, portanto, merecedores de proteção.

$\mathrm{Na}$ década de 1970 aconteceu uma ruptura que põe de um lado a psicologia dita positivista, ocupada especialmente da pesquisa empírica e de outro a psicologia dita crítica mais próxima, em termos de objeto e metodologia de pesquisa, das ciências sociais (Jacques et al., 2014). Na mesma época, se desenvolveu no Brasil o cam- 
po interdisciplinar dos estudos de gênero, que inclui, embora com menor força, a psicologia social crítica após a sua ruptura com a corrente anglo-saxã (Borges, 2014; Nuremberg, Toneli, Medrado, \& Lyra, 2011). Embora existam hoje muitos grupos de pesquisa que dedicados ao estudo das relações de gênero, sobretudo na psicologia social, a constatação atual é de que não existe, no Brasil, um campo de estudos reconhecido e institucionalizado como a psicologia feminista norte-americana (Nuremberg et al., 2011). Além disso, as contribuições feministas são pequenas na psicologia brasileira empírica, na qual gênero raramente é considerado uma categoria analítica (Narvaz \& Koller, 2007). Isso significa dizer que ainda não ocorreu no Brasil um processo compreensivo de revisão das teorias e práticas psicológicas, dentre elas, a avaliação psicológica com sua tradição na criação e no uso de instrumentos para avaliação do gênero.

Portanto, o persistente uso de testes como o CPS no Brasil parece se relacionar ao fato de, ao contrário do contexto norte-americano de onde esses instrumentos são oriundos, os estudos feministas na psicologia social e a avaliação psicológica se consolidaram com poucas interfaces e com bases epistemológicas distintas. Dessa forma, áreas da psicologia brasileira como a avaliação psicológica, resistem à modificação do padrão binário classificatório. Além do CPS, a primeira versão do MMPI foi recentemente readaptada para o contexto brasileiro sem críticas em relação à escala $\mathrm{M}$ e seu histórico de avaliação da orientação sexual enquanto uma patologia (Figueiredo, 2012). Tal trabalho foi, paradoxalmente, vencedor da $7^{a}$ edição do prêmio Silvia Lane, prêmio que leva o nome de uma das fundadoras da psicologia social crítica brasileira. Além disso, o BSRI também foi readaptado recentemente (Hernandez, 2009). Tal adaptação serviu como ponto de partida para criação de um novo instrumento (Barros, Natividade, \& Hutz, 2013), que ao contrário das inovações presente na proposta original do BSRI, não leva em consideração as categorias "indiferenciada" e "andrógina", se aproximando do modelo unidimensional, e quase centenário, das escalas de Terman e Milles. No entanto, mais grave é o exemplo já apresentado do CPS, pois se trata de medida reconhecida institucionalmente pelo Conselho Federal de Psicologia.

Costa e Nardi (2013) avaliaram uma medida de heterossexualidade aprovada pelo Conselho Federal mostrando que um dos pressupostos para a avaliação dos instrumentos psicológicos no Brasil é a equivalência entre critérios técnicos e éticos. Ou seja, a ideia de que ao apresentar boas propriedades psicométricas (critérios técnicos) o instrumento estaria automaticamente de acordo com os direitos humanos, por exemplo (critérios éticos). No entanto, os autores demonstraram que um instrumento poderia estar em harmonia com os critérios técnicos e, portanto, com o sistema regulatório e, mesmo assim, estar em desacordo com critérios éticos flagrantes. $\mathrm{O}$ mesmo se aplica ao CPS. O instrumento fere a dignidade das mulheres ao associar a feminilidade a estereótipos negativos ao assumir que as mulheres que não tem medo de insetos e répteis e não gostam de histórias românticas podem ser desajustadas, anormais ou até doentes. Além disso, o emprego desse instrumento em processos seletivos fere o direito de igualdade se utilizado como motivador para reprovação com base na omissão da diversidade de gênero. Fere também a liberdade individual, uma vez que não é o sujeito, mas é o/a psicólogo/a especialista que detêm a verdade - nesse caso bastante parcial - sobre o gênero. Por fim, expõe uma parcela da população trans a constrangimentos desnecessários já que não há outra opção além de se identificar com o modelo teórico (binário) do instrumento.

$\mathrm{Na}$ disponibilidade de conhecimentos atualizados, não parece ser aceitável, por exemplo, submeter a população a procedimentos médicos, como uma cirurgia, utilizando técnicas ultrapassadas. Na psicologia, não se trata apenas do uso de uma medida antiquada (o CPS é baseado em uma teoria de 1948!), é mais grave, pois as categorias utilizadas para descrever os sujeitos têm implicação na forma como eles se constroem enquanto tal. O tipo de avaliação do CPS não leva em conta a autodesignação e não contribui para a construção da igualdade entre homens e mulheres, trans e cis, pelo contrário, trata-se de uma estratégia perigosa que restringe a autonomia 
dos sujeitos e reforça estereótipos arcaicos. Portanto, é fundamental que as práticas psicológicas, com especial ênfase as medidas de avaliação de gênero sejam revistas à luz do conhecimento contemporâneo apresentado até aqui. É como esse intuito que reproduzimos o gesto simbólico que Phyllis Chesler e Nancy Henley realizaram em 1970, dirigido agora ao Conselho Federal de Psicologia:

A psicologia brasileira tem sido criminosa em sua maneira de se relacionar com homens e mulheres, trans e cissexuais. Ela tem perpetuado a ideia cruel de que as pessoas não são autônomas para determinar o seu gênero, sugerindo sem bases científicas o que seria um corpo, uma identidade e uma performance de gênero normal; ela participou da prisão psicológica e física de inúmeras pessoas, especialmente trans, quando as rotulou de mentalmente incapazes por causa de sua recusa em cumprir as exigências injustas e ilegítimas impostas sobre elas. Chegou o momento para os psicólogos e psicólogas começarem a reparar os danos que eles e elas causaram e de inverter a direção das forças já em curso que visam aprisionar mentes e corpos.

\section{Referências}

American Psychological Association. (1975). Report of the task force on sex bias and sex-role stereotyping in psychotherapeutic practice. American Psychologist, 30(12), 1699-1175. doi:10.1037/0003-066X.30.12.1169

Barros, M. C., Natividade, J. C., \& Hutz, C. S. (2013). Construção e validação de uma medida de papéis de gênero. Avaliação Psicológica, 12(3), $317-324$

Benjamin, H. (1966). The transsexual phenomenon: A scientific report on transsexualism and sex conversion in the human male and female. New York: Julian Press

Bem, S. L. (1974). The measurement of psychological androgyny. Journal of Clinical and Consulting Psychology, 42(2), 155-162. doi:10.1037/ h0036215

Bem, S. L. (1977). On the utility of alternative procedures for assessing psychological androgyny. Journal of Clinical and Consulting Psychology, 45(2), 196-205. doi:10.1037/0022006X.45.2.196
Borges, L. S. (2014). Feminismos, teoria queer e psicologia social crítica: (Re) Contando histórias... Psicologia \& Sociedade, 26(2), 280-289. doi:10.1590/S0102-71822014000200005

Bockting, W. (2009). Transforming the paradigm of transgender health: A field in transition. Sexual \& Relationship Therapy, 24(2), 103-107. doi:10.1080/14681990903037660

Chrisler, J. C., de las Fuentes, C., Durvasula, R. S., Esnil, E. M., McHugh, M. C., Miles-Cohen, S. E., ...Wisdom, J. P. (2013). The American Psychological Association's Committee on Women in Psychology 40 Years of Contributions to the Transformation of Psychology. Psychology of Women Quarterly, 37(4), 444-454. doi: $10.1177 / 0361684313505442$

Cohen-Kettenis, P. T., \& Pfäfflin, F. (2010). The DSM diagnostic criteria for gender identity disorder in adolescents and adults. Archives of Sexual Behavior, 39, 499-513. doi:10.1007/s10508009-9562-y

Coleman, E., Bockting, W., Botzer, M., CohenKettenis, P., DeCuypere, G., Feldman, J., ...Monstrey, S. (2012). Standards of care for the health of transsexual, transgender, and gendernonconforming people, version 7. International Journal of Transgenderism, 13(4), 165-232. doi $: 10.1080 / 15532739.2011 .700873$

Comrey, A. L. (1970). Construct validation of the Comrey Personality Scales. Multivariate Behavioral Research, 5(4), 469-477. doi:10.1207/ s15327906mbr0504_5

Comrey, A. L. (2008). The Comrey personality scales. In G. J. Boyle, G. Matthews, \& D. H. Saklofske (Eds.), The SAGE handbook of personality theory and testing: Vol 2. Personality measurement and assessment (pp. 113-134). Thousand Oaks, CA: Sage.

Condry, J., \& Condry, S. (1976). Sex differences: A study of the eye of the beholder. Child Development, 47(3), 812-819. Retrieved from http:// www.jstor.org/stable/1128199

Conselho Federal de Psicologia. (2013a). Psicologia: Uma profissão de muitas e diferentes mulheres. Brasília, DF: Autor.

Conselho Federal de Psicologia (2013b). Resolução CFP $n^{\circ}$ 002/2003. Define e regulamenta o uso, a elaboração e a comercialização de testes psicológicos e revoga a Resolução CFP 
$n^{\circ}$ 025/2001. Recuperado em http://site.cfp. org.br/wp-content/uploads/2003/03/resolucao2003_02_Anexo.pdf

Conselho Federal de Psicologia. (s.d). Nota técnica sobre processo transexualizador e demais formas de assistência às pessoas trans. Recuperado em http://site.cfp.org.br/wp-content/ uploads/2013/09/Nota-t\%C3\%A9cnica-processo-Trans.pdf

Constantinople, A. (1973). Masculinity-femininity: An exception to a famous dictum? Psychological Bulletin, 80(5), 389-407. doi:10.1037/ h0035334

Costa, A. B., \& Nardi, H. C. (2013). Diversidade sexual e avaliação psicológica: Os direitos humanos em questão [Número especial]. Psicologia: Ciência e Profissão, 33, 124-137.

Costa, F. R. (2009). Escala de Personalidade de Comrey - CPS $3^{a}$ edição. São Paulo, SP: Vetor.

Darwin, C. (1933). A descendência do homem e a seleção sexual. Rio de Janeiro, RJ: Marisa. (Trabalho original publicado em 1871)

Davidson, M. (2007). Seeking refuge under the umbrella: Inclusion, exclusion, and organizing within the category transgender. Sexuality Research \& Social Policy, 4, 60-80. doi:10.1525/ srsp.2007.4.4.60

Diamond, L. M. (2009). Sexual fluidity. Cambridge, MS: Harvard University Press.

Drescher, J. (2010). Queer diagnoses: Parallels and contrasts in the history of homosexuality, gender variance, and the Diagnostic and Statistical Manual. Archives of Sexual Behavior, 39(2), 427-460. doi:10.1007/s10508-009-9531-5

Drescher, J., Cohen-Kettenis, P., \& Winter, S. (2012). Minding the body: Situating gender identity diagnoses in the ICD-11. International Review of Psychiatry, 24(6), 568-577. doi:10.3109/095402 61.2012.741575

Eagly, A. H. (1987). Sex differences in social behavior: A social-role interpretation. Hillsdale, NJ: Lawrence Erlbaum.

Eagly, A. H., Eaton, A., Rose, S. M., Riger, S., \& McHugh, M. C. (2012). Feminism and psychology: Analysis of a half-century of research on women and gender. American Psychologist, 67(3), 211-230. doi:10.1037/a0027260

Ellis, H. (2013). Inversão sexual. Lisboa: INDEX ebooks. (Original publicado em 1927)
Fausto-Sterling, A. (2008). Myths of gender biological theories about women and men, revised edition. New York: Basic Books.

Figueiredo, K. M. (2012). Estudo das propriedades psicométricas do Inventário Multifásico Minnesota de Personalidade (MMPI) [Monografia]. Recuperado em http://premiosilvialane.abepsi. org.br/vencedores-7-edicao/VENCEDORES-KELYANE\%20MADUREIRA-TCC.pdf

Fleming, M. Z., Jenkins, S. R., \& Bugarin, C. (1980). Questioning current definitions of gender identity: Implications of the Bem Sex-Role Inventory for transsexuals. Archives of Sexual Behavior, 9(1), 13-26. doi:10.1007/BF01541398

Foucault, M. (1998). História da sexualidade: A vontade de saber. Rio de Janeiro, RJ: Graal.

Foucault, M. (2004). A ética do cuidado de si como prática da liberdade. In M. Foucault, Ditos \& Escritos $V$ - Ética, sexualidade, política (pp. 265288). Rio de Janeiro, RJ: Forense Universitária.

Freud, S. (2011). Sobre a psicogênese de um caso de homossexualidade feminina. In S. Freud, Psicologia das massas e análise do eu e outros textos (1920-1923) (pp. 114-149). São Paulo, SP: Companhia das Letras (Original publicado em 1920)

Galton, F. (1869). Hereditary genius. London: Macmillan and Company.

Gilman, S. L. (1985). Difference and pathology: Stereotypes of sexuality, race and madness. Ithaca, NY: Cornell University Press.

Guilford, J. P., \& Zimmerman, W. S. (1949). The Guilford-Zimmerman Survey: Manual of instructions and interpretations. Beverly Hills, CA: Sheridan Supply.

Hacking, I. (1995). The looping effects of human kinds. In D. Sperber, D. Premack, \& A. J. Premack (Eds.), Causal cognition: A multidisciplinary debate. Symposia of the Fyssen Foundation (pp. 351-394). New York: Oxford University Press.

Hacking, I. (2004). Historical Ontology. Cambridge, MS: Harvard University Press.

Hacking, I. (2007). Kinds of people: Moving targets. Proceedings-British Academy, 151, 285-318.

Hall, G. S. (1904). Adolescence: Its psychology and the relation to physiology, anthropology, sociology, sex, crime, religion and education. New York: Appleton. 
Hathaway, S. R., \& McKinley, J. C. (1940). A multiphasic personality schedule (Minnesota): I. Construction of the schedule. Journal of Psychology, 10, 249-254.

Hegarty, P., \& Buechel, C. (2006). Androcentric reporting of gender differences in APA journals: 1965-2004. Review of General Psychology, 10(2), 377-389. doi:10.1080/00223980.1940.99 17000

Herdt, G. H. (1996). Third sex, third gender: Beyond sexual dimorphism in culture and history. New York: Zone Books.

Herman-Jeglińska, A., Grabowska, A., \& Dulko, S. (2002). Masculinity, femininity, and transsexualism. Archives of Sexual Behavior, 31(6), 527534. doi:10.1023/A:1020611416035

Hernandez, J. A. E. (2009). Reavaliando o Bem Sex-Role Inventory. Estudos de Psicologia (Campinas), 26(1), 73-83. doi:10.1590/S0103$-166 \times 2009000100008$

Hill, D. B., \& Willoughby, B. L. (2005). The development and validation of the genderism and transphobia scale. Sex Roles, 53(7-8), 531-544. doi:10.1007/s11199-005-7140-x

Hollingworth, L. S. (1914). Variability as related to sex differences in achievement. American Journal of Sociology, 19, 510-530. doi:10.1086/212287

Hooker, E. (1957). The adjustment of the male overt homossexual. Journal of Projective Techniques, 21(1), 18-31. doi:10.1080/08853126.1957.1038 0742

Hooker, E. (1958). Male homosexuality in the Roscharch. Journal of Projective Techniques, 22(1), 33-54. doi:10.1080/08853126.1958.10380822

Jacques, M. D. G. C., Guareschi, P. A., Carlos, S. A., Bernardes, N. M. G., Fonseca, T. M. G., \& Strey, M. N. (2014). Psicologia social contemporânea. Rio de Janeiro, RJ: Vozes.

Katz, J. (1996). A invenção da heterossexualidade. Rio de Janeiro, RJ: Ouro.

Kessler, S. J. (1990). The medical construction of gender: Case management of intersexed infants. Signs, 16(1), 3-26. doi:10.1086/494643

Kessler, S. J. (1998). Lessons from the Intersexed. New Brunswick, NJ: Rutgers University Press.

Kessler, S. J., \& McKenna, W. (1978). Gender: An ethnomethodological approach. Chicago, IL: University of Chicago Press.
Kinsey, A. C., Pomeroy, W. B., \& Martin, C. E. (1948). Sexual behavior in the human male. Philadelphia, PH: W. B. Saunders.

Krafft-Ebing, R. F. (2011) Psychopathia Sexualis. São Paulo, SP: Martins Fontes. (Original work published 1886)

Langlois, J. H., \& Downs, A. C. (1980). Mothers, fathers, and peers as socialization agents of sex-typed play behaviors in young children. Child Development, 51(4), 1237-1247. doi:10.2307/1129566

Laqueur, T. (2001). Inventando o sexo: Corpo e gênero dos gregos a Freud. Rio de Janeiro, RJ: Relume Dumará.

Lippa, R., \& Connelly, S. (1990). Gender diagnosticity: A new Bayesian approach to gender-related individual differences. Journal of Personality and Social Psychology, 59(5), 1051-1065. doi:10.1037/0022-3514.59.5.1051

Mead, M. (2011). Sex and temperament in three primitive societies. New York: Harper Perennial. (Original work published 1935)

Minton, H. L. (2000). Psychology and gender at the turn of the century. American Psychologist, 55(6), 613-635. doi:10.1037/0003066X.55.6.613

Money, J., \& Ehrhardt, A. A. (1972). Man \& woman, boy \& girl: The differentiation and dimorphism of gender identity from conception to maturity. Baltimore, MA: Johns Hopkins University.

Money, J., Hampson, J. G., \& Hampson, J. L. (1955). An examination of some basic sexual concepts: The evidence of human hermaphroditism. Johns Hopkins Hospital Bulletin, 97(4), 301-319.

Money, J., Hampson, J. G., \& Hampson, J. L. (1957). Imprinting and the establishment of gender role. Archives of Neurology \& Psychiatry, 77(3), 333-336. doi:10.1001/archneurpsyc.1957.02330330119019

Morawski, J. G. (1985). The measurement of masculinity and femininity: Engendering categorical realities. Journal of Personality, 53(2), 196-223. doi:10.1111/j.1467-6494.1985.tb00364.x

Muehlenhard, C. L., \& Peterson, Z. D. (2011). Distinguishing between sex and gender: History, current conceptualizations, and implications. Sex Roles, 64(11-12), 791-803. doi:10.1007/s11199011-9932-5 
Narvaz, M. G., \& Koller, S. H. (2007). A marginalização dos estudos feministas e de gênero na psicologia acadêmica contemporânea. Psico, 38(3), 216-223.

Nuremberg, A. H., Toneli, M. J. F., Medrado, B., \& Lyra, J. (2011). Feminism, Psychology, and Gender Studies: The Brazilian Case. In A. J. Marsella (Ed.), Handbook of international feminisms international and cultural psychology (pp. 109-127). New York: Springer.

Pereira, D. F., \& Bandeira, D. R. (2009). Aspectos práticos da avaliação psicológica nas organizações. São Paulo, SP: Vetor.

Pickren, W., \& Rutherford, A. (2010). A history of modern psychology in context. Hoboken, NJ: John Wiley \& Sons.

Rodrigues, A. (1979). As escalas de personalidade de Comrey (CPS): Desenvolvimentos recentes e novos grupos normativos. Arquivos Brasileiros de Psicologia, 31(4), 155-166.

Serano, J. (2007). Whipping girl: A transsexual woman on sexism and the scapegoating of femininity. Berkley, CA: Seal Press.

Shields, S. (1975). Functionalism, Darwinism, and the psychology of women. American Psychologist, 30, 739-754.

Shields, S. A. (1982). The variability hypothesis: The history of a biological model of sex differences in intelligence. Signs, 30(7), 769-797. doi:10.1037/h0076948

Shields, S. A., \& Dicicco, E. C. (2011). The Social Psychology of Sex and Gender from gender differences to doing gender. Psychology of Women Quarterly, 35(3), 491-499. doi:10.1177/0361684311414823

Silverman, L. K. (1989). It all began with Leta Hollingworth: The story of giftedness in women. Journal for the Education of the Gifted, 12(2), 86-98. doi:10.1177/016235328901200202

Spence, J. T. (1993). Gender-related traits and gender ideology: Evidence for a multifactorial theory. Journal of Personality and Social Psychology, 64(4), 624-635. doi:10.1037/00223514.64.4.624

Spence, J. T. (2011). Off with the old, on with the new. Psychology of Women Quarterly, 35(3), 504-509. doi:10.1177/0361684311414826
Spence, J. T., \& Buckner, C. E. (2000). Instrumental and expressive traits, trait stereotypes, and sexist attitudes: What do they signify? Psychology of Women Quarterly, 24(1), 44-53. doi:10.1111/j.1471-6402.2000.tb01021.x

Staum, M. S. (2003). Labeling people: French scholars on society, race and empire, 1815-1848. Montreal, QC: McGill-Queen's University Press

Tate, C. C., Youssef, C. P., \& Bettergarcia, J. N. (2014). Integrating the study of transgender spectrum and cisgender experiences of selfcategorization from a personality perspective. Review of General Psychology, 18(4), 302312. doi:10.1037/gpr0000019

Terman, L. M., \& Miles, C. C. (1936). Sex and personality: Studies in masculinity and femininity. New York: McGraw-Hill.

Thompson, H. B. (1903). The mental traits of sex. Chicago, IL: University of Chicago Press.

Unger, R. K. (1979). Toward a redefinition of sex and gender. American Psychologist, 34(11), 10851094. doi:10.1037/0003-066X.34.11.1085

Ussher, J. M. (2013). Diagnosing difficult women and pathologising femininity: Gender bias in psychiatric nosology. Feminism \& Psychology, 23(1), 63-69. doi:10.1177/0959353512467968

Valentine, D. (2007). Imagining transgender: An ethnography of a category. Durham, NC: Duke University Press.

Von Hohendorff, J. (2014). Como escrever um artigo de revisão de literatura. In S. H. Koller, M. C. P. P. Couto, \& J. V. Hohendorff (Eds.), Manual de produção científica (pp. 39-54). Porto Alegre, RS: Penso.

Weinberg, G. (1972). Society and the healthy homosexual. New York: St. Martin's Press.

Will, J. A., Self, P. A., \& Datan, N. (1976). Maternal behavior and perceived sex of infant. American Journal of Orthopsychiatry, 46(1), 135-139. doi:10.1111/j.1939-0025.1976.tb01234.x

Recebido: 28/09/2015

$1^{a}$ revisão: 16/01/2016

Aceite final: 22/01/2016 